\title{
ASPECTOS SEMÁNTICOS Y LÉXICOS DEL ESPAÑOL DE PUERTO RICO
}

\author{
María AZuCEna Penas Ibáñez \\ Universidad Autónoma de Madrid. Grupo Sem.Lat.Rom. \\ azucena.penas@uam.es
}

\begin{abstract}
Resumen
La mezcla de culturas en Puerto Rico a lo largo de su historia (aborigen, española, africana, estadounidense) ha enriquecido notablemente su léxico y ha permitido que Luis Rafael Sánchez ejercite su capacidad de crear neologismos, de jugar con los vocablos (especialmente nombres y verbos), recreándolos en su forma y en su significado, como vamos a comprobar con algunos ejemplos. En este artículo nos centraremos en los aspectos morfológicos y sintácticos del léxico, pero, muy especialmente, en los semánticos, sin incidir, sin embargo, en condicionantes dialectológicos o idiolectales.

PALABRAS CLAVE: léxico, semántica, morfología léxica, sintaxis, español de América.
\end{abstract}

\begin{abstract}
The mixture of cultures in Puerto Rico through its history (native, Spanish, African and North American cultures) has made its lexicon richer and has allowed Luis Rafael Sánchez to create neologisms, to play with the form and the meaning of the words -especially names and verbs-, and its peculiar uses, just as examples show. This article is focused on morphological, syntactic and, above all, semantic aspects of the lexicon, not paying a special attention to dialectal or idiolectal questions.
\end{abstract}

KEYWORDS: lexicon, semantics, lexical morphology, syntax, Spanish of America.

\section{Introducción ${ }^{1}$}

Puerto Rico es una de las islas más extensas de las Antillas. El español y el inglés son sus lenguas oficiales. Su población ha heredado, además, bastante léxico perteneciente a sus antepasados aborígenes y al proveniente del contingente africano. Esta mezcla de culturas a lo largo de su historia (aborigen, española, africana, estadounidense) ${ }^{2}$ ha enriquecido notablemente su léxico y ha servido de base para que un prestidigitador de la palabra puertorricense como es Luis Rafael Sánchez, ejercite su capacidad de crear neologismos, de jugar con los vocablos recreándolos en su forma y en su significado, como

\footnotetext{
${ }^{1}$ Este artículo forma parte de un Proyecto de Investigación cofinanciado por la Universidad Autónoma de Madrid y la Comunidad Autónoma de Madrid, del cual soy la investigadora responsable, titulado "Semántica y sintaxis de los verbos con doble participio en español: herencia latina e indoeuropea en la diátesis y en la voz" (Clave 1003040011).

${ }^{2}$ En el presente estudio abordaremos primero, la influencia cultural española; segundo, la estadounidense; tercero, la aborigen; y cuarto, someramente, la africana y la de otros países exóticos, atendiendo al espacio que representan en los textos analizados.
} 
vamos a comprobar con algunos ejemplos ${ }^{3}$. Para ello desglosaremos nuestro trabajo atendiendo a dos aspectos, ya prefijados desde el título: el léxico-semántico, sobre todo el nominal, neologista y recreador, y el sintáctico-semántico, centrado en los usos peculiares, novedosos, de las construcciones verbales, prestando especial atención a las participiales, con respecto al español de España, con lo que dejaremos en un segundo plano el hecho de que el carácter novedoso de los términos presentados aquí sean por causa dialectal (variante puertorriqueña), o por motivos idiolectales (variante de autor), ya que lo que perseguimos no es tanto una investigación contrastiva dialectológica o estilística, aunque tampoco la excluimos, sino, sobre todo, léxica y semántica.

\section{El componente léxico-semántico}

\subsection{Español}

En él encontramos nombres como: disqueros (11); almaceneros (43); musiquero, carrero (126), con sufijo - ero aplicado a disco, a almacén, a música, a carro, un sufijo muy extendido en la zona ${ }^{4}$; incluso se dice temporero (214), por 'temporal', sin la especialización semántica del término temporero: 'persona que ejerce un trabajo temporalmente', como, por ejemplo, antes, los trabajadores de la zafra. El DRAE registra disquero para el español de América nada más; en concreto, Cuba, Venezuela y Uruguay. En el DEA sí aparece reflejado como entrada léxica del español de España, pero con connotación de uso raro: 'pinchadiscos `. El sufijo -ón, -ona, también es muy característico del español del Caribe, sobre todo asociados a ciertos lexemas nominales como sabrosona, dulzona, mamasona (101), fabulón (159), por 'fabuloso'. Este sufijo es usado como comparativo de superioridad del sustantivo; por ejemplo: qué ratón bueno vamos a pasar (146), en lugar de la expresión 'qué rato más bueno vamos a pasar', que sería la usual en el español de España. La formación de sustantivos difiere de la norma de España, en casos como prometimientos (20), por 'promesas'; ansiosidad (22), por 'ansiedad', al derivar a partir del adjetivo ansioso y no del sustantivo primitivo ansia; usante (29), por 'usuario'; bobación (59), por 'bobería'; nación (62), por 'nacimiento', originándose una homonimia enojosa con la acepción $1^{\text {a }}$ de nación; linduras (64), por 'lindezas'; mensualidad (64), por 'menstruación', con una especialización semántica que no posee en el español de España. Además se genera una polisemia nueva en el término mensualidad; llagosidad (115), por 'llagamiento`; risería (118), por 'risa'; fumadera, inyectadura (126), por las voces españolas específicas para la droga 'porro', 'chute'; una picoreta (143), por 'una chismosa', palabra metonímico-metafórica, al establecerse una doble relación entre 'chisme $\leftarrow$ boca $\rightarrow$ pico'; secretividad (151), por 'secreto'; opinionera (154), como sustantivo colectivo, 'conjunto de opiniones'; arrebatación (157), por 'arrebato`; juntillas (189), por 'camaradas,

\footnotetext{
${ }^{3}$ Cito por la edición de la novela La guaracha del macho Camacho, que figura en la bibliografía. El número hace referencia a la página.

${ }^{4}$ Obsérvese que en Cuba también se dice música santiaguera. Curiosamente se da una especialización léxica de acuerdo con el topónimo. Así, santiagueses los de Santiago de Compostela, santiagueños los de Argentina, santiagueros los de Cuba, y santiaguinos los de Chile.
} 
compinches, compañías', con base también metonímica; clandestinaje (197), por 'clandestinidad; tomada de pelo (215) por 'tomadura de pelo'; razonilla (230) por 'excusa'; malezal (240), por 'maleza', en sentido colectivo; platería (251), por 'plata'. Por otra parte, hay casos de sustantivos donde, no la formación sino la pronunciación americana, difiere de la española, como choferes $^{6}$ (96), por 'chóferes'. En el siguiente sintagma nominal con valor interjectivo-vocativo, hay amalgama, ya lexicalizada ${ }^{7}$, por contracción entre determinante posesivo y núcleo: mija (178).

En cuanto a los adjetivos, también su formación, en algunos casos, difiere de la norma de España: musicosa $a^{8}$ (23), por 'musical'; abejosa (48), por 'de abejas'; labioso (87), por 'cuentero, mentiroso, fequero', palabra únicamente metonímica, al establecerse la relación entre 'mentira $\leftarrow$ labio'; comelones (37), por 'comilones', con vacilación de vocales átonas, inducida a su vez por transparencia de significante con respecto al significado 'comer'; autística (96), por 'autista', con neutralización de clasemas cosa/persona; insaboro (126), por 'insípido', sobre el esquema analógico de inodoro, incoloro; cosmopolitano (230), por 'cosmopolita'; también difiere el régimen de los adjetivos y participios adjetivales con respecto a la norma de España: pendiente a la machería (203), por 'pendiente de los machos '; así mismo se observa cambio de género tanto en los colectivos ${ }^{9}$, como en gentuzo (24), en España 'gentuza'; el cosecho (132), por 'la cosecha'; tropelio (244), por 'tropelía', quizá en este último ejemplo, se dé también una etimología popular sobre lío; como en los no colectivos: el llamado (98), por 'la llamada'; se registra formación de femeninos analógicos sobre los que se crean masculinos regresivos: animalo ${ }^{10}$ irredento (38), por 'animal irredento'; masculino regresivo también en cabro (60), por 'macho cabrío', o en parejo $^{11}$ (227), por 'pareja masculina'. Igualmente, es frecuente la utilización de formas adjetivo-adverbiales para marcar las perífrasis aspectuales terminativas: recién ha dado a la imprenta un tomo antológico de prosa, en el sentido de 'acaba de dar a la imprenta un tomo antológico de prosa'; o la anteposición del adverbio de cantidad al pronombre indefinido negativo: más nadie (215), de posible influjo portugués; abunda la neutralización de cuál (217) por 'qué en cuál político honesto no tiene andado el Getsemaní, ya que no subyace el sentido de elección, sino de ponderación negativa, al modo de una pregunta retórica. Por otra parte, constituyen neologismos: microfoniáticos (11), mixónimo ${ }^{12}$ de micrófono + maniático; pesámica (73), mixónimo de pesada + mesiánica; macharranes (87), mixónimo

\footnotetext{
5 El propio autor nos da metalingüísticamente su sinónimo en la novela: "no urdió excusa o razonilla". Semánticamente razonilla puede explicarse al descodificarla sémicamente en 'razón ' + ' menor'.

${ }^{6}$ Más adelante en la pág. 150 aparecerá un derivado sinonímico, quizá idiolectal, choferío.

${ }^{7}$ Lexicalización que se manifiesta incluso ortográficamente.

${ }^{8}$ El sufijo - osa puede connotar estilísticamente una música pegadiza 'pegajosa'.

${ }^{9}$ Aunque no hay cambio de género, sí presenta un cambio léxico: genterío (220) por 'gentío', forma, esta última, usada en España.

${ }^{10}$ Hay un caso muy curioso en la novela: Ciela (51), voz polisémica y anfibológica, ya que significa: Cielo y Graciela, por aféresis hipocorística.

${ }^{11} \mathrm{Si}$ en parejo o en cabro las referencias léxicas existen bajo la forma de cabra, sustantivo marcado como femenino, y pareja, sustantivo epiceno en cuanto al género, en animalo nos encontramos con una elaboración genérica más compleja, que, reconstruida a partir de la palabra existente, quedaría así: 'animal $>$ animalo $>$ animala'.

${ }^{12}$ También llamado acrónimo.
} 
de macho + charrán + muchacho; blancusinas (108), mixónimo de blanca + venusina; infidencias (131), mixónimo de infidelidad + incidencia; lechoza (138), mixónimo de lechuza + lechosa 'papaya'; amontoñados (176), mixónimo de montaña + montón; cachendoso (205), mixónimo de cachondo + cadencia; meaíto (207), mixónimo ${ }^{13}$ de medianito + meadito; mediotónica (223), mixónimo de a medio tono + mitad tónica; se avalancharon (243), mixónimo de avalancha + abalanzarse; Hay casos de derivación adjetiva también novedosa en claxónico (68), por 'de claxon'; multitud autosa...encochetada ${ }^{14}$ (68), por 'en auto, en coche'. Neologías serían también los casos de culiguardadas $^{15}$ (18), por 'vírgenes reprimidas', donde también se observa un uso deponente activo del participio, puesto que no son guardadas por, sino que son ellas las que guardan o se guardan el culo de; ha mapeado (18), por 'ha barrido del mapa, ha arrasado, ha gustado mucho'. Curiosamente el autor ha procedido onomasiológicamente, y no es el único caso ${ }^{16}$ en la novela, aportando el sinónimo estándar a la forma usada en Puerto Rico, que permite una correcta descodificación en el español de España, sin necesidad de consultar un diccionario de americanismos; guarachaba (14), verbo denominal, que designa tanto el baile como el son: 'bailar y sonar la guaracha'. En España sólo se emplean las perífrasis anteriores. El término guaracha -en Cuba y Puerto Rico, baile semejante al zapateado, un tanto procaz ${ }^{17}$, se consolida como un foco expansivo de derivación, ya que sobre él se crea también un adjetivo nominalizado guarachómano (21), un derivado de guaracha + -ómano, sufijo que connota 'adicción` por asociación con la formación de términos como heroinómano, cocainómano..., y no simplemente 'afición', como podría ser su origen etimológico en melómano. Con ello se nos está indicando que la guaracha actúa como una droga nacional; también el adjetivo derivado guarachil (68) y el sustantivo guaracheo (220). Otros verbos denominales los tenemos en ritmar (241), proveniente de ritmo, el ritmo de la guaracha, o vellonear (241), proveniente de vellonera (239), también referido a la guaracha. Por otra parte, Vacilón (14), sustantivo deverbal, del verbo vacilar, en la acepción de 'pasarlo bien'. El uso en Puerto Rico es nominal: 'fiesta, goce, jolgorio'. En España, en cambio, su forma es claramente adjetiva. Arrecuérdate que... (15) presenta una amalgama de acordarse de que + recordar que, que constituye una forma híbrida, novedosa; como también esfuerzan, un híbrido de 'fuerzan con esfuerzo'; escupiteje (70), sobre el sustantivo escupitajo, por 'escupa', única forma verbal en España; me abajo y me

\footnotetext{
${ }^{13}$ En cambio, en salgo de deudas (207), no hay mixonimia entre *deudas y *dudas, sino asociación fónicosemántica por isotopía textual, propiciada por la frase y perífrasis verbal salir de dudas.

${ }^{14}$ Obsérvese la paronomasia que se puede establecer con encorsetada, encorchetada. La afinidad de significantes da margen para ello.

${ }^{15}$ Sobre el mismo esquema culidando (241), por 'dando al culo'.

${ }^{16}$ Series sinonímicas del tipo: a mi todo plin, a mi todo me resbala, a mí todo me las menea, a mi me importa todo un mojón de puta (24), son frecuentes. O como orador... charlista (29), o como cortejas y querindangas (38), más adelante continúa con otros sinónimos, como barragana, mantenida, querida (94). También hay casos de listas de sinónimos continuados, no a través del tiempo, como en el caso anterior, sino a través del espacio: truenos, relámpagos, centellas (98), eurekas, cáspitas, recórcholis, canastos (99), coñus, carajus, puñetum (99); siendo, además, a diferencia de los sinónimos anteriores, sinónimos funcionales en el texto por el contexto.

${ }^{17}$ De hecho el propio autor dice en un momento dado de la novela: esa jacarandosa y pimentosa, laxante y edificante, profiláctica y didáctica, filosófica y pegajosófica guaracha del Macho Camacho (39). Los términos subrayados connotan, un tanto libidinosos, picardía sexual y lujuriosa, relajo.
} 
asubo (221), por 'me bajo y me subo'. Muy posiblemente no sean variantes idiolectales, sino sociolectales, adscritas a la clase popular ${ }^{18}$ a la que pertenecen, por otra parte, los personajes que las profieren.

Variantes sociolectales populares, características del español antillano y caribeño, de clara influencia meridional española en algunos casos, serían también los fenómenos fonéticos de apócope de consonante final, como reló, (15) por 'reloj; la síncopa de la -dintervocálica, tanto en nombres como en verbos: peo, (17) por 'pedo', 'borrachera'; sujetá (201), por 'sujetada'; el lavao, el planchao, el cocinao (201), por el 'lavado', el 'planchado', el 'cocinado'; tiene que pagarla bien pagá (61), por 'pagada'; pelúas (61), por 'peludas ; la síncopa de muta cum líquida y posterior sinéresis en pai (62), por 'padre'; los güevines, por 'huevines' (107), con anáptixis de la velar oclusiva sonora; o la epéntesis de la velar oclusiva sonora por asimilación de la labiovelar wau: mariguano (242), derivado de 'marihuana'; rolos (119), por 'rulos', donde se puede rastrear una etimología popular por asociación con rodar, dada su forma esférica; e incluso culantro ${ }^{19}$ (178), por 'cilantro', variante popular sinonímica de cilantro, a la que subyace textualmente una posible etimología popular con culo; el seseo $^{20}$ : felisss como una lombrisss ${ }^{21}$ (139); la simplificación de la sibilante africada en fricativa, como en clisés (157); la vocalización del grupo consonántico pl- : piace (201), por 'place'; la neutralización de /1/ y /r/: almario (219); treintitrés (226), por 'treinta y tres', donde se aprecia una monoptongación vulgar. Así como los fenómenos sintácticos de la contracción de para el en pal (62), por amalgama; la reduplicación de la forma pronominal en construcciones verbales seudopronominales, como lo que me tengo que treparme, aguantarme, llegarme (17), por 'lo que tengo que trepar, aguantar, llegar', que sería el único empleo en el español de España, y, en cualquier caso, si se quisiera enfatizar, nunca se reduplicaría la forma pronominal; la extensión analógica del morfema gramatical $-s$ de $2^{\mathrm{a}}$ persona de singular a la única forma del paradigma verbal que no lo presenta: planchastes (73), por 'planchaste'; el uso dequeísta: recuerdo de que un mes después de la boda (107), influido por el régimen preposicional de otro verbo de su mismo campo semántico, acordarse de.

Retomando los neologismos -todos ellos variantes idiolectales-, comprobamos que demuestran gran ingenio y habilidad lingüísticos. Podemos citar: adoratriz (17), que como femenino alternativo de adoradora, en este caso de Iris Chacón, es una forma que estilísticamente está marcada en oposición a admiradora, fan, más esperables, ya que

\footnotetext{
${ }^{18}$ Según de Granda (1968: 124, 177, 179) el uso del español en Puerto Rico se ve relegado fundamentalmente al ámbito de lo oral, lo coloquial y lo familiar, de ahí que llegue a plantear un proceso de dialectalización, mediante vulgarismos y localismos, que pudiera desembocar incluso en fenómenos de jerga y diglosia.

${ }_{19}$ Curiosamente el autor retoma la forma patrimonial más próxima a la etimología de la palabra para marcar distancias, provocando la hilaridad, con respecto a la forma generalizada de cilantro, que etimológicamente está más distanciada de su étimo coriandrum, ya que para llegar a ella se necesita apelar al influjo analógico del término celidonia, planta empleada también en medicina (cfr. Corominas y Pascual, 1980, II, pág. 286)

${ }^{20} \mathrm{El}$ seseo, en sí, es una característica dialectal fonética del español caribeño, así como la aspiración de la $-\mathrm{S}$ implosiva: que pa eso somos jamericanos (215), marcada hábilmente por la grafía (j), de la velar fricativa sorda, en un claro proceso de simplificación fonética.

${ }^{21}$ El texto nos ofrece una nota metalingüística y dialectal acerca del seseo en Puerto Rico, cuando leemos: "nacionaliza la zeta y confronta un superávit de eses" (139).
} 
condensa en su forma dos significados asociados por el significante: 'adoradora de la artista, de la actriz', 'su fan'; sintácticas o sintáxicas (74), donde se expresa, casi como propuesta léxica para quien quiera recoger el testigo, el neologismo junto a la palabra estándar. Cápsulas de jodeina (37), sobre el modelo 'cápsulas de codeína', para referirse irónicamente a una dama de la alta sociedad que representa bien las palabras de la canción de Cecilia: "dama, dama, de alta cuna, de baja cama..."; poderes vatisos (61), por 'poderes de vate'; mamismo (70), por 'excesiva influencia y poder de mamá'; camisas mamitoescas (140), por 'hechas por y al gusto de mamá'; encontramos tautologías sintáctico-léxicas del tipo: lo incomoda, la incomodidad..., lo fastidia, el fastidio..., lo revienta, el reventón..., lo jodifica, la jodificación ${ }^{22} \ldots$, le jitea las bo, el jiteo, le cachea las las, el cacheo..., le jona, la jonación...,(67), en donde los términos subrayados indican un mayor esfuerzo estilístico; así como, expresiones tautológicas afines como me discute discutidamente (111), donde apreciamos una tautología léxica; espíritu malgenioso (97), donde tenemos una tautología semántica, basada en una relación de hiperonimia-hiponimia, y, además, una probable relación antonímica nueva sobre 'ingenioso'; horror dráculo (103), donde, a través de un proceso de antonomasia se crea una sinonimia funcional entre dráculo y 'muy grande $>$ el mayor', que, a su vez, resulta pleonástico de horror, descodificable en 'sentimiento de aversión ' + 'muy grande + 'muy intenso'. Curiosamente al ser modificado por el adjetivo dráculo, que funciona en la tautología semántica como un epíteto, invade el significado de 'terror', descodificable en 'miedo' + 'muy grande + 'muy intenso', que no posee, aunque sí le es afín metonímicamente: 'terror $\rightarrow$ horror'; hallamos acumulación excesiva, anormal, de formas nuevas, como en: la excesividad del frío la causifica la cheverosidad de nuestro acondicionante de aires ${ }^{23}(106)$; también, registramos adverbialización en -mente sobre lexema sustantivo, no adjetivo o adjetivo-participial: cucarachamente (130), con el significado de 'al modo de una cucaracha'; pugilateo (130), por 'pugilato', para marcar así el aspecto frecuentativo reiterativo que se desea imprimir en el sustantivo existente; metábasis de sustantivo por adjetivo, basada en la metonimia: recuerdo Kodak (137), por 'recuerdo fotográfico'; patilla operática (141), por 'de ópera'; escalada everéstica (141), por 'escalada al Everest', con connotaciones sexuales, apoyadas en el sustantivo implícito monte, asociado a su vez a 'monte de Venus'; también con connotaciones eróticas bicicleta con agilidad maratónica el cuerpo de la autora (141), con uso del verbo bicicletar, inexistente en el español de España, por 'montar en bicicleta'; Doña Chon, bombástica (181), por 'ocurrente', como cuando se dice "esto es la bomba". Se da un caso muy novedoso de creación adjetiva por analogía con el sustantivo primitivo que le sirve de base para la derivación: cosas de muchacho travieso, travesuras de muchacho coso (189); se observa creación de palabras por analogía fonética con otras con las que teje isotopías semánticas: pendango (199), por 'pendejo', sobre fandango; sexocolor (200), sobre technicolor; ustedeo...cameo...pideo...exigeo ...pagueo... ¿bieneo? (200), sobre tuteo, desde la formulación cortés, muy irónica, que se está adoptando, puesto que se pone en evidencia que es un 'usted nada respetable ni respetado'; Hay un caso de composición tipográfica muy

${ }^{22}$ Donde subyace una asociación verbal irónica con verbos y sustantivos de significado y estereotipo contrarios como edificar, edificación; santificar, santificación.

${ }^{23}$ Donde se destruye la lexía aire acondicionado. 
novedosa por ser toda una oración: Vicenteesdecente (215), o todo un encadenamiento lúdico de pronombres-artículos homónimos: sácala la brújula al viéntolo y sábela dóndela sóplala (217); También hay casos de composición léxica nueva, aunque sobre esquemas analógicos empleados por la lengua: fototeca (252), sobre patrones ya existentes como, por ejemplo, fonoteca; incluso, el poder creativo de Luis Rafael Sánchez se atreve a morfofonologizar un nuevo género, el *neutro, que parece reivindicar en el siguiente ejemplo, a través de /e/ > [-e]: Lola no es Lola, Lola no es Lolo, Lola es Lole : un mariconazo hormónico y depilado (219).

\subsection{Estadounidense}

Hay abundantes casos de anglicismos-americanismos ${ }^{24}$ directos, como palabras: show (17), clubman (27), darling (29), shirt (67), champions (67), furnished (85), mainly,(106), feeling (135), Mother (137); Halloween (145); Thanksgiving (146), subway (154), tellers (154), man (186), basement (199), nice (202), Hello (224), Dear (231) ; y como expresiones, tanto del discurso repetido ${ }^{25}$ : candy store (19), made in Puerto Rico (27), latin lover (28), Happy Birthday (69), high life (106), corn flakes (118), wash and wear (128), sweetie pie (146), fun and games (153), Campbell Vegetable Soup (204), Anchors Away My Boys, From the Halls of Moctezuma, Over Hills (212), scrap book (216), Buxeda Funeral Home (217), Wall Street (225), Garden Hills (232), pool party (232), pretty people...very adorable people (232), stress (232); como del discurso libre: a sort of fucking superstar (28); the very casual look (41); un cigarrillo Winston tastes good like a cigarette should (81); People have got to know whether or not their President is a crook. Well, I'm not a crook (161); in spite of himself (175); dirty bunch they are (202); Honey, I don't blame you. The whole damn thing is your nerves (232); y anglicismos-americanismos adaptados, como jipi (21); crayón (48); tofes (87); parkin (150); cofibreiks (156); líder (156), boul (202); clubes (230). En ese proceso de adaptación se observan casos de hibridismo ${ }^{26}$ inglésespañol: party con cake (70), los Flying Saucers del Ringling Brothers Circus (95), un get together, cold cuts (129), un set de pantalones (206), parejo available (227), Mrs. Cuca White, Mrs. Pitusa Green, Mrs. Minga Brown, Mrs. Fela Florshein (230), Casa Club (230); o casos de solapamiento entre ambos códigos: una libra de moscas (241), donde existe la duda de si hace referencia a un arcaísmo español como 'peso antiguo de Castilla, dividido en 16 onzas y equivalente a $460 \mathrm{~g}$. ', o si hace referencia al inglés 'pound, a modo de calco semántico $^{27}$. También hay calcos sintácticos del inglés, como cinco pasado meridiano de

\footnotetext{
${ }^{24}$ La influencia angloamericana está presente en un hibridismo cultural, a través de un proceso de transmisión de valores o transculturación, según término empleado por de Granda (1968: 99-100).

${ }^{25}$ Hay dos ejemplos que no pertenecen al discurso repetido propiamente, ya que no permiten una traducción satisfactoria por el significante, aunque sí por el significado al no haber un proceso metafórico consolidado de lexicalización, que entrarían dentro de la onomástica de los nombres propios a modo de marcas comerciales, como son: First National City Bank (151) y Esso Standard Oil Company (151).

${ }^{26}$ Hibridismo que en muchas ocasiones resulta diglósico a favor del inglés.

27 De Granda (1968), dentro del proceso de convergencia con respecto al inglés, distingue cuatro aspectos: préstamos léxicos, calcos semánticos, gramaticalización de posibilidades expresivas paralelas a las inglesas e interferencias sintácticas.
} 
miércoles hoy (22), iniciada y conducida por los grupos antisociales (30), en lugar de 'iniciada y dirigida...', mira un poco a poco traído son (30), con una anteposición forzada del adyacente, en lugar de 'mira un son traído poco a poco', ¿... qué usted quiere decir? (244), sobre el esquema what do you want to say? ${ }^{28}$ Una variante de calco sintáctico podría ser aprovechar estilísticamente un cliché lingüístico para modificarlo, como en yankees, this is home (29), sobre el modelo de la expresión hecha yankees, go home; otro calco lo tenemos en tomará un examen final (129), por 'tendrá un examen final' y en la investigación de la bomba no tomará un año (214), por 'no llevará un año'.

También hay términos del spanglish ${ }^{29}$, como friquiterías (17), por 'excentricidades, rarezas`. En el español de España se ha incorporado últimamente el préstamo friqui, con el mismo significado, pero todavía no ha desarrollado derivación nominal; tipos bien Wilson (26), por 'hombres atractivos, guapos, con dinero, siguiendo el prototipo de galán americano'; gufeo (31), por 'pifia o mentecatería'; teletipa el pensamiento (38), por 'mecanografía el pensamiento'; un down en su orgullito, por 'un golpe bajo en su orgullito'; Misis (46), por 'señorita'; tineger (74), por 'adolescente', me pongo isi, rilás, redi (87), por 'easy, relaxed, ready'; es decir, 'fácil, relajada, preparada'; Barbizon School of Modelling (125), por 'Escuela de modelos al estilo Barbie'; closet (128), por 'retrete, servicio'; hizo un fotuto (154), por 'hizo un aspaviento'; los jambergues (177), por 'las hamburguesas'. Incluso, hay una aproximación metalingüística al spanglish, como es el caso de en idioma inglés chapurreado, en idioma inglés metralla: excuse me (179), o Excuse me -dijo la Madre, en su inglés de a dos chavos- (238). Igualmente hay casos de cruces semánticos por influjo del inglés sobre el español: pujar (240), con el significado de 'empujar' (push), con especialización semántica en Cuba, Costa Rica, El Salvador, Nicaragua y Venezuela, donde adquiere el sentido de 'emitir un sonido o voz particularmente característicos, cuando se hace un gran esfuerzo o se soporta un dolor', como sí es el caso del texto, ya que está referido al parto. En España también ha adquirido un sentido especializado, pero, en las tareas crematísticas de economía y bolsa: 'hacer una puja, por ejemplo, en una subasta'.

\subsection{Aborigen.}

Aquí incluimos tres tipos de ejemplos:

(a) americanismos léxicos, o sea, palabras que no existen tal cual en el léxico del español de España: faca churrasqueira ${ }^{30}(103)$, $_{\text {chavos }}^{31}$ (139), platanutre (139), por 'rueda fina de plátano verde, frita y espolvoreada con sal', a lo sисиsитиси (163),

\footnotetext{
${ }^{28}$ Aunque también podría ser un factor coadyuvante el propio español de América, ya que en él suena rudo el sujeto pospuesto en una pregunta.

${ }_{29}$ Refleja un bilingüismo incipiente, principalmente entre aquellos que, aunque no son capaces de componer en inglés frases y textos dotados de sentido (requisito indispensable para se incluidos entre los bilingües "subordinados", según terminología de Haugen, 1956 y Weinreich, 1958), manejan palabras y expresiones sueltas de este idioma.

${ }^{30}$ Se observa en el sufijo - eira una influencia portuguesa-brasileira.

${ }^{31}$ Con el significado genérico en Puerto Rico de 'dinero', si va en plural, y con el significado particular de 'centavo de dólar', si va en singular. Curiosamente en esta última acepción no significa 'ochavo', que sería su etimología.
} 
según el DRAE en Colombia y Puerto Rico 'a la chita callando', asopao ${ }^{32}$ de pollo, dron de mondongo (177), butucún de pan con ajo, funche (179), cuatro ejemplos de gastronomía típica de Puerto Rico, tongonea (175), según el DRAE en Venezuela '(se) contonea', ejemplo que posiblemente acuse una onomatopeya de base, ya que el contoneo viene asociado con el ruido de los tacones al andar así, y también permite una asociación por etimología popular con otra palabra afín tanto fónicamente como semánticamente, como es tongo, puesto que al contonearse se le está lanzando al varón una trampa o señuelo para que pique. Por otra parte, como voz puertorriqueña el DRAE registra dita (116), por 'vasija hecha de la segunda corteza del coco o de la corteza de la güira', también como voz puertorriqueña y cubana el DRAE registra sato (119), por 'gato o perro pequeño, de cualquier color y pelo corto, vagabundo, y en el caso del perro, ladrador', guagua (127), término usado tanto en Canarias como en las Antillas, estofón (129), según el DRAE voz usada en Puerto Rico, por 'empollón', cheverón (131), fracatán (142), según el DRAE voz usada en Puerto Rico y R. Dominicana, por 'sinnúmero', bembeteo ${ }^{33}$ (154), según el DRAE en Cuba y Puerto Rico 'chismorreo', cachanchana (202), según el DRAE en Cuba 'persona adulona', cheveresco $^{34}$ (209), chamacos (251);

(b) americanismos semánticos; es decir, palabras existentes en el español de España, pero que han adquirido una acepción americana, como sucede en: pesos (18), por 'unidad monetaria en América', bolero (127), por 'canción y baile caribeño', zafacones $^{35}$ (145), según el DRAE en Puerto Rico y R. Dominicana 'recipiente para recoger las basuras', tortillas de maíz ${ }^{36}(162)$, gavetero (186), según el DRAE en Cuba, Panamá y Puerto Rico 'mueble con gavetas', gaveta (238), camarón (193),

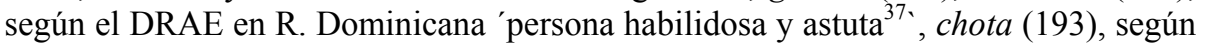
el DRAE en Puerto Rico 'persona floja, pusilánime; persona falta de habilidad', aguaje (199), según el DRAE en Cuba y Puerto Rico 'bravuconada', chinas $^{38}$ (205), según el DRAE en Puerto Rico 'naranjas dulces', monga $^{39}$ (212), según el DRAE en

\footnotetext{
${ }^{32}$ Asopao, aunque etimológicamente proviene de sopa, no designa esa realidad sino un 'estofado', como sucede con el término portugués ensopado.

${ }^{33}$ Existe en España la forma onomatopéyica bezo con el significado de 'labio grueso', con la que está emparentada.

${ }^{34}$ Esta palabra es polisémica ya que ha adoptado distintas acepciones en América. Concretamente en el Caribe actualiza el significado de 'estupendo, buenísimo, excelente', acepción que está presente en el texto. En Puerto Rico y Venezuela también puede adquirir el significado de 'petimetre'.

${ }^{35}$ En España existe dialectalmente la forma de origen árabe zafa en Albacete, Granada y Murcia con el significado de 'jofaina'.

${ }^{36}$ Obsérvese que aquí no es permutable maíz por patata, ya que el huevo no se comparte en ambas recetas. En cambio en papitas fritas (162), sí se comparten patatas y aceite. Ahora bien, no hay coincidencia léxica entre papas y patatas, ya que la $1^{\text {a }}$ forma es dialectal americana y meridional española, y la segunda forma es la estándar en el español de España. Tampoco hay coincidencia designativa en la fritura puesto que el aceite no es necesariamente de oliva.

${ }^{37}$ Palabra que ofrece un espectro semántico muy amplio en el español de América. Tanto es así que representa en ocasiones los polos opuestos, como sucede en Ecuador, donde significa 'conductor inexperto'.

${ }^{38}$ Existe una palabra homónima, proveniente del quichua čina, 'hembra, sirvienta'.

${ }^{39}$ Derivado de mogo, ga, que, a su vez, es un derivado regresivo de mogollón, cuyo étimo árabe ha penetrado catalanizado o italianizado. El eslabón semántico lo encontramos tanto en la acep. 4 'lío, jaleo', como en la acep. 3 de la loc. adv. 'mal, descuidadamente o con apresuramiento'.
} 
Puerto Rico 'débil', en Cuba 'tonta'. Esta última acepción conviene más al texto de L.R. Sánchez: pelea monga, es decir, 'pelea tonta', uvero (219), derivado de uva, con el significado de 'árbol silvestre de la familia de las Poligonáceas, que vive en las costas de las Antillas, Venezuela y América Central... Su fruto es la uva de playa', trillita (251), según el DRAE en Andalucía, Chile y Puerto Rico 'zurra, felpa, pateadura', con un significado figurado sobre la palabra primitiva trilla, de la que deriva; colmados (252); pantaletas (253), por 'bragas', charrasqueado (253), voz onomatopéyica que actualiza el significado ${ }^{40}$ caribeño de 'rasgueado de las cuerdas de un instrumento musical y de ahí, metonímicamente, 'música, baile'. Dentro de este grupo de americanismos semánticos podemos incluir aquellas palabras plenamente insertas en el léxico español, con mayor o menor uso generalizado, pero que connotan un significado americano. Vendrían a ser una especie de subtipo de falso amigo, pero dentro de una misma lengua con respecto a dos variantes dialectales: la española chicana (199), que actualiza en el texto el significado de 'broma, chanza', incluso 'artimaña', proveniente del étimo francés chicane; y la americana, proveniente del acortamiento del étimo mexicano, na, pues, dada la homonimia del término, connota el significado de 'perteneciente o relativo a la minoría de origen mexicano en Estados Unidos ', chinas $^{41}$ (205), según el DRAE en Puerto Rico 'naranjas dulces'; y

(c) indigenismos léxicos: bayoya (31), yuyos (33), tainería (94), Manatuabón y Otoao (94), combo (101), catingoso (105), Guajataca (106), comala (110), Tlaloc, Quetzalcoatl (110), mangle (116), borinqueños (137), de Borinquén, antiguo nombre de la isla de Puerto Rico, ceiba (143), boricua (154), borincano (215) por 'puertorriqueño', nopales (161), ñapa (188), cumbanchera ${ }^{42}$ (190), según el DRAE en Cuba y México 'juerguista, parrandera', chaucha (201), por 'moneda, dinero', antillano (202), guayabera, guayaba, batata (203), Moctezuma (212), macanas (214), hicacos (219), cachipa, guarapo (241), mafafa (242), maní (242).

\subsection{Africano y de otros países exóticos}

Registramos africanismos léxicos, como bongó (23), Tombuctú (93), dinga (94), guineos (116), afro (153), africanía (230), cafrería (253). Se da algún caso de voces provenientes del tagalo y el bisaya, como sunsunbabaé (153), por 'mujeriego, al son de la mujer'; así como alusivos al chino: chinos (206), y procedentes del portugués de Brasil: menina (216), del portugués de Portugal: coco (241), del francés: bonhomía (218), charme (225), souvenir (227), Oui (252), o del italiano: vendetta (230).

\footnotetext{
${ }^{40}$ Otra rama semántica la encontramos, también por vía onomatopéyica, en México: 'que tiene una cicatriz de herida con arma blanca'.

${ }^{41}$ Existe una palabra homónima, proveniente del quichua čina, 'hembra, sirvienta'.

${ }^{42}$ Posiblemente voz proveniente de cumbo, ba (quizá del maya cum, 'calabaza'). De aquí podemos diseñar la siguiente correlación: 'torcido' $\rightarrow$ 'que no es recto' $\rightarrow$ 'adulación' $\rightarrow$ 'piropo, lisonja, requiebro' $\rightarrow$ 'fiesta, jolgorio '.
} 


\subsection{Léxico erótico}

Dentro del componente léxico-semántico merece una mención aparte las denominaciones tan variadas que presenta el órgano reproductor masculino, en detrimento del femenino.

Así, con respecto al masculino la sinonimia funcional es tan abundante que permite la siguiente clasificación:

$\left(\mathrm{a}_{1}\right)$ términos figurados metonímicos cultos: sexos peludos y alongados (34), lugar innombrado (103), la molleración protuberante (140), partes pudebundas ${ }^{43}$ (141), por partes pudendas en España, el animal insomne puesto de pie (153), invade la pubescencia (186), mixónimo de púber + excrecencia;

$\left(\mathrm{a}_{2}\right)$ términos figurados metonímicos coloquiales, incluso vulgares: chiringa excitada (117), el colgajo (138), la pinga (162);

$\left(\mathrm{a}_{3}\right)$ términos figurados metonímicos familiares: rascarme la puntita de (130), abandonar la posición hidalga de pipí parado o paradito (138);

$\left(\mathrm{b}_{1}\right)$ términos figurados metafóricos cultos: obsceno pájaro de la noche (46), la bestia que dormita en cada hombre (105), instrumenta el solo de clarinete (200);

$\left(b_{2}\right)$ términos figurados metafóricos vulgares, incluso coloquiales: animalo ${ }^{44}$ irredento (91), los aspavientos del tolete (146), cojón (217), polla (243);

$\left(b_{3}\right)$ términos figurados metafóricos familiares: la dureza mediana del oficiante (186);

(c) términos seudolatinos: carajus (99).

En cambio, con respecto al femenino los sinónimos son más escasos:

$\left(\mathrm{a}_{1}\right)$ términos figurados metonímicos cultos: sexos peludos y cavernosos (34);

$\left(b_{1}\right)$ términos figurados metafóricos cultos: el pozo del pecado (249);

$\left(\mathrm{b}_{2}\right)$ términos figurados metafóricos vulgares, incluso coloquiales: descoñada (48), joyo (130), coño (243);

$\left(\mathrm{b}_{3}\right)$ términos figurados metafóricos familiares: el lindo rotito del lindo culito (57);

(c) términos perónimos eufemísticos: el conducto membranoso y fibroso que se extiende desde la vulva hasta la matriz (141), el instrumento de trabajo (249);

(d) términos seudolatinos: coñus (99).

También aparecen verbos, de base metonímico-metafórica, como chichar (141), por 'copular', dar chino a alguien (145), por 'darle con el culo, acercársele con insinuaciones lascivas'.

\footnotetext{
${ }^{43}$ Quizá haya cruce con nauseabundas, propiciando una polisemia sintáctica y un juego de palabras.

${ }^{44}$ Donde a su vez se puede ver una relación hiperonímico-hiponímica: animalo/pájaro. Obsérvese por otra parte el avance, coloquial, de la moción o flexión genérica en animal > animalo, inducida no solo paradigmáticamente, sino también sintagmáticamente por pájaro.
} 


\section{El componente sintáctico-semántico}

En él hallamos un uso frecuente de elipsis:

(a) por reticencia oracional: el aforismo cumbre o uno de los (14); Dice, redice, maldice y no se arranca algunos pelos porque algunos pelos tiene, habilísimamente dispuestos y fijados con laca ${ }^{45}$ naturalidad por la recomendación estilista de un barbero metido a $(27)^{46}$, la estudiante... reverencia la guaracha del Macho Camacho, como reverencian la guaracha del Macho Camacho los cientos de choferes que. (99);

(b) por abreviación, mediante acortamiento sintagmático nominal: un Ferrari es una aeronave bien fabu (74); en el monumental supermercado donde se apertrechaban de comestibles los ri y los que tenían sus pe en el ban (205);

(c) por elipsis prepositiva: descontado que (206), en lugar de 'por descontado que'.

En cuanto a la esfera verbal es también muy frecuente en todo el español del Caribe el uso transitivo de verbos que rigen preposición, como quiere encargarla del despacho de (19), por 'quiere que se encargue de', 'quiere hacerle encargo de', 'quiere encargarle de', según el contexto; adueñan las islas estivales (212), por 'se adueñan de las islas estivales ${ }^{\wedge 7}$, verbo que en España es pronominal; o el uso transitivo de verbos perifrásticos: señoronas que letanían el qué me pongo (41), donde se usa el verbo letaniar, por 'decir en letanía'; o el uso transitivo de verbos que en España siempre serían pronominales ${ }^{48}$ o de régimen preposicional, como liga una estudiante (96), por 'se liga a una estudiante', o 'liga con una estudiante'; o el uso transitivo de verbos que en España serían factitivos: para que las mujeres nos crezcamos el busto y el caderamen (115), por 'para que las mujeres nos hagamos crecer... o nos dejemos crecer' o donde el sujeto semántico (nosotras, las mujeres) sería en realidad un objeto indirecto sintáctico: 'para que a las mujeres nos crezca...'; o el uso transitivo de verbos que en España serían intransitivos impersonales: rocear (206), por 'regar', en español 'lloviznar'; o el uso transitivo de verbos intransitivos personales: pelear (216), por cruce con 'disputar', presentando, quizá una impropiedad semántica; o la utilización de verbos denominales que provienen de sustantivos de perífrasis verbales, por procedimiento sintético, constituyendo una integración lingüística: diarrearse (150), por 'tener diarrea', prensar (191), por 'contar en la prensa', engafarse (203), por 'ponerse las gafas ', sonambular (229) por 'andar sonámbulo', posesionar (229) por 'tomar posesión de', mansionar (231) por 'dar albergue, morada suntuosa, mansión', cronicar (190), por 'contar

45 Resulta muy creativa esta forma, ya que puede ser el sustantivo laca, motivado semánticamente y designativamente por el participio inmediato: fijados, y puede ser una extensión fónica del determinante la dentro del sintagma nominal la naturalidad, convertido en laca naturalidad.

${ }^{46}$ Quizá no sea un caso de reticencia, sino de hipérbaton + hipálage, que reordenados, quedarían así: '... por la recomendación de un barbero metido a estilista`.

${ }^{47}$ Cabría la posibilidad de la perífrasis atributiva ser dueño(a)s de.

${ }^{48}$ También se da el caso contrario, uso intransitivo de verbos que en España siempre son pronominales, como resintiendo (242), por 'resintiéndose', 'sintiéndose resentido (a)', 'quedando con resentimiento'. 
en una crónica', desde una perspectiva activa, o cronicar (232), por 'aparecer en la crónica', desde una perspectiva pasiva, muecar (242), por 'hacer muecas'; o el uso coloquial-vulgar de la apócope de formas verbales del presente, del tipo diz que (37); o el uso coloquial-vulgar dequeísta: ella gusta ${ }^{49}$ de comer (59), por 'a ella le gusta comer'; o el uso de verbos sin prefijación lexicalizada: trampado en la garganta convidaba al vómito (6162), por 'entrampado, atrampado, en este último caso, cruce también con atrapado ; o el uso de prefijación para negar un verbo que antepone el adverbio de negación: inaceptar (149), por 'no aceptar'; o la reducción prefijal en algunos verbos: desbrochó (203), por 'desabrochó', desdibujándose la idea de 'abrochar', y potenciándose la idea de 'broche'; o el incremento prefijal: despaciar (241), por 'espaciar'; o, incluso, el uso normativo diferente de los prefijos verbales: apertrechaban (205), por 'pertrechaban'; o la desemantización del prefijo: recesar (250), por 'cesar temporalmente en sus actividades', no por 'volver a cesar', como en España; o la distinta derivación verbal, simplificando el aspecto frecuentativo: rumorar (229) por 'rumorear'; o el uso neutralizante de ser por estar en construcciones copulativas con atributo adverbial bien: no es bien que todo muchacho de dieciocho años no tenga su maquinón (188); o el predominio en las formas del pasado del pretérito perfecto absoluto simple de indicativo sobre, como es el caso, del pret. imperfecto de subjuntivo, dándose una neutralización de ambas formas: Las Polacas pujaron tanto... que me hicieron que a una de las Polacas se le reventó un vasito de sangre de tanto pujar (240), por 'se le reventara'; o la especialización semántica de verbos como votar ${ }^{50}$ (64), por 'echar', manejar un carro (95), por 'conducir un coche'.

Con respecto a las construcciones de participio se registran los siguientes fenómenos:

(a) utilización de participios de pasado permutables en el texto por perífrasis adverbiales: recatadas (13), por 'con recato', sudada (13), por 'con sudor', sentada (15), por 'en un asiento', parada (15), por 'sin movimiento', alcoholado (17), por 'con alcohol', 'que contiene alcohol', acaneladas (33), por 'de color canela', isla de cemento nombrada Puerto Rico (34-35), por 'de nombre Puerto Rico', mucha señora deprimida (47), por 'con depresión', respuestas seriadas (84), por 'respuestas en serie', la voz argentada (86), por 'la voz de plata', muñeca trajeada de sevillana (113), por 'muñeca en traje de sevillana', la tarde apurada (117), por 'la tarde con prisa', las voces descreídas (117), por 'las voces sin fe', primos desclasados (140), por 'primos sin clase', gafas ahumadas (140), por 'gafas de color de humo', resumido (163), por 'en resumen', criatura desconsolada (226), por 'criatura sin consuelo', acalorada, renegada, descreida (243), por 'con sofoco, sin conformidad, sin fe', deshuesados (244), por 'sin hueso'; o permutables por perífrasis verbales: vaporado el eructo (23), por 'hecho vapor el eructo', testimonios juramentados (30), por 'testimonios avalados con juramentos'; o permutables por frases comparativas: apelotonada (13), por 'como una pelota'; o permutables por un adjetivo calificativo: duchada (15), por 'limpia', de hombre público y privado (16), por 'no público', conminación velada (17), por 'indirecta', el domingo pasado (64), por 'el domingo

\footnotetext{
${ }^{49}$ Obsérvese la influencia del inglés en la construcción del verbo gustar con pronombre personal sujeto, y no complemento indirecto.

${ }^{50}$ De origen marinero. El significado de 'echar' se conserva en gallego y portugués de Portugal y de Brasil.
} 
anterior', almendrados (81), por 'llenos de almendros', qué respuestas abrasadas ${ }^{51}$ ... qué recibimientos cálidos (156), por 'respuestas tórridas', el botiquín atestado de esponjas (156), por 'repleto de esponjas', una laxitud tan fabricada (165), por 'tan artificial, el café ralo o el café cargado (166), por 'no ralo', espécimen de mensura parecida (224), por 'igual o semejante', ideas nobles y elevadas (251), por 'excelsas';

(b) hay también casos de uso deponente del participio de pasado: ella ... reída con jajá ostentoso y dientes por docenas (14), por 'habiéndose reído', le viene un eructo cocacolizado (22), por 'con regusto ${ }^{52}$ a Coca-Cola', la nómina reñida de los hombres mejor vestidos del país (35), por 'nómina elitista, exclusiva', con premura sexuada (38), por 'premura de tener sexo', azorada, tremulante, llorosa, resiste la provocación... (46), como se ve, combinable con participio de presente tremulante y adjetivo activo llorosa; la audiencia sonreidísima (65), por 'que se sonríe mucho y constantemente', la jodida culpa (108), por 'la fastidiosa culpa', desayunada con corn flakes (118), por 'habiendo ya desayunado', color sufrido (123), por 'color que sufre, que aguanta las manchas, es decir, color oscuro o negro', por la encendida calle (125), por la 'calurosa calle'. Incluso hay un ejemplo que podríamos denominar metalingüístico, al ser explicado desde la propia lengua: el certificado brilloso que certifica (164);

(c) se detecta algún caso de impropiedad semántica: o sea Papi, que la juventud te estaremos agradada (76), por 'agradecida', sobre el cruce de 'sentir agrado y sentir gratitud', o la juventud moderna está necesaria de oídos (187), por 'necesitada de oídos', o una preñada antojada (239), por 'antojadiza', es decir, 'que tiene antojos ${ }^{53}$ con frecuencia';

d) también se detecta algún caso de neutralización entre pasiva y activa: un abrazo y dos llantos sonados y temblados (103), por 'sonoros y temblorosos', Vicente es decente y razonado hasta la muerte (214), por 'razonador o razonable ${ }^{54}$;

(e) se observan igualmente algunos ejemplos muy curiosos en los que el autor nos ofrece la doble perspectiva diatética: activa-pasiva, unas veces marcada por sustantivo-verbo: en la pantalla panorámica de su encocoramiento, la tardanza del Viejo organiza la reflexión encocorada de ella (15-16), lleva anillo de casada, la mano anillada (82), con disimulo bien disimulado (108), izado por el horror y horrorizado (150), bromas asi tienen lugar en el pasaje embromado de todas las épocas (251). Hay casos donde esta doble perspectiva diatética se establece pleonásticamente entre participio y complemento agente: la querella fue desoída por juez desoidor (193), la Metafísica fue desoída por funcionarios desoidores (250).

\footnotetext{
${ }^{51}$ Paronomasia con abrazadas.

${ }^{52}$ No es un caso de diátesis, sino de deixis inversa: 'gusto devuelto'. También estamos ante un ejemplo de deixis inversa en: ruindad de los niños sobrantes que apostados en una chorrera contemplan el gozo y lo gozan. Como se puede comprobar en ambas estructuras subrayadas se mantiene el complemento directo como tal, sin transformarse en sujeto paciente.

${ }^{53}$ En 'tener antojos' se rastrea semánticamente una perspectiva pasiva: 'padecerlos, sufrirlos, soportarlos'.

${ }^{54}$ El sufijo - able remite a su vez a construcción pasiva.
} 
Incluso viene marcada la doble perspectiva diatética por sustantivo-verbo-verbo: humor llamado sudor brotando a chorros ... plano primerísimo de un poro sudado... plano primerísimo de un poro sudando (141); otras veces marcada por sustantivoadjetivo-verbo, en una serie muy novedosa: en mahones y polo short... zapatos tennis, también llamados zapatos champions (67)... Benny, mahonado, polado, championado (68), o solo por sustantivo-sustantivo: como obra en un acto para dos actores (199); y otras veces, señalada por verbo-verbo, a través de participio de presente-participio de pasado: de distinta familia léxica: secretaria eficiente $y$ ratificada por los cursillos (47), de tu azotea pensante, de tu cráneo engrasado (76), o de la misma familia léxica: efervescencia del animalo irredento, efervescido y efervescente (91), caricias desesperadas y desesperantes (142), incluso con tipografía focalizada: Graciela se detiene fas-ci-na-da, he-chi-za-da, em-bru-ja-da, a mirar la fascinante, hechizante, embrujante fotografia de la casa de Liz y Richard en Puerto Vallarta (110); a través de forma personal-participio de pasado: de la misma familia léxica: desanuda la corbata que lo guillotina: guillotinado ${ }^{55}$ por Oscar de la Renta (28), y la risa se me enredaba en el cuerpo como bejuco y enredada como bejuco... (81), enjorquetada en una silla que enjorquetó en la butaca (114), el que pone a mirar la vida desde cerca y desde lejos y la vida mirada desde lejos... (135), Graciela edita orgasmos inéditos (162), chilla chillada (163), un apéate ${ }^{56}$... Apeado (192), se calló. Callada, Graciela (232), clama uno, clamado con coño de apellido (243), o de distinta familia léxica: me papeo una latita de jamón picao ${ }^{57}$ : relamida (139), chilla dolida, chilla resentida (163). Incluso un ejemplo estilísticamente tan conseguido como le pusieron a la Metafísica, en el pozo del pecado, una barra de estrellas de las que alegran y despiden y alumbran el año viejo, barra de estrellas que convirtió a la Metafísica en puta iluminada. La Metafísica, luchadora japonesa, no pudo luchar con justeza, el instrumento de trabajo chamuscado $(249)^{58}$. También se dan casos, algunos muy elaborados, a través de formas no personales, como: participio de futuro pasivo-participio de pasado, de la misma familia léxica: Benny no formó parte de clase graduanda alguna aunque se graduó (127), o como: infinitivo-participio de pasado, de la misma familia léxica: piel sin inmutarse, piel inmutada (177), dijo Doña Chon, mirándola retorcerse, mirándola deshacerse, mirándola contorsionarse, mirándola restregarse, mirándola desbaratarse... dijo (la Madre) retorcida, dijo deshecha, dijo

\footnotetext{
${ }^{55}$ Hemos registrado un ejemplo, a través de gerundio-participio, donde se expresa todo el recorrido diatético: dijo Doña Chon, el húmero comiéndole los ojos... los ojos comidos por el húmero (177-178).

${ }^{56}$ Encontramos otro caso de sustantivación en: si no clavo la paleta hasta donde dice: usted acaba de efectuar la clavada perfecta (185), reproduciendo en el enunciado el estilo directo de la enunciación.

${ }^{57}$ Textualmente lo tomamos como un participio de pasado que funciona como adjetivo, ya que establece antonimia funcional con el adjetivo entero.

${ }^{58}$ Obsérvese el proceso diatético sugerido semánticamente, aunque no expresado como tal sintácticamente, desde una pluriperspectiva de: estrellas-alumbran, Metafisica = puta-iluminada, el instrumento de trabajo-chamuscado, cómo culmina en un resultado: alumbran $\rightarrow$ iluminada $\rightarrow$ chamuscado.
} 
contorsionada, dijo restregada, dijo desbaratada ${ }^{59}$ (244), o como participio de futuro pasivo-participio de presente-participio de pasado, de distinta familia léxica: una educanda solvente y respetada (104); otros ejemplos se construyen a través de adjetivo-verbo: de la misma familia léxica: Mimoso mimado (119), observadores imparciales imparcializados (213), o de distinta familia léxica: la palabra otoñal la atosiga de recuerdos conmovidos, recuerdos lastimosos (167), Doña Chon ... invicta hacedora de rellenos de papa (177). En este apartado de adjetivo-verbo, encontramos un ejemplo más elaborado, donde se opone pasiva entusiasmado a activa, y dentro de esta última se diferencia la perspectiva interior-estática entusiasta de la exterior-dinámica entusiástico (231). En los siguientes ejemplos hallamos adjetivos resultativos ${ }^{60}$ que presuponen un participio en construcción pasiva: hijo adoptivo de siete pueblos (30), que presupone 'que ha sido adoptado por siete pueblos', católico práctico (59), permutable por es versado, es experimentado, porque presupone 'que ha practicado', 'practica', y sobrentiende 'que practicará'.

El siguiente ejemplo aporta una nota más al proceso diatético, al ofrecer el doble enfoque instrumental y agentivo ${ }^{61}$ con respecto al participio: Sheila lo capó por un tiempo, capado con seis letras... capado por Sheila (252). Incluso en otro ejemplo se nos aporta el enfoque de complemento de origen, no agentivo, a partir de un modal-instrumental previo: serpiente que latiga con sabor, Benny latigado de sabor (255);

(f) Igualmente, se constata la doble perspectiva, pero ahora, entre pasiva o media, a la hora de interpretar los ejemplos siguientes: respaldo de una vida encuadernada con planchas de decencia (49), por 'que ha sido encuadernada', como pasiva, o quizá mejor, por 'que se ha encuadernado', como media. Este doble enfoque, pasivo o medio, viene expresado no sólo, como en el caso anterior, sintácticamente, sino

\footnotetext{
${ }^{59}$ Constituye toda una correlación, con abundante sinonimia que funciona como una isotopía semántica reforzadora de coherencia textual.

${ }^{60}$ Incluso se dan casos de construcciones resultativas que presuponen construcciones de proceso: el vaniti se cerró o el vaniti quedó cerrado (48), donde 'quedó cerrado 'presupone el proceso de 'se cerró', despatarrando y resbalando y cayendo y cayendo y cayendo: caído y vomitando el rabo (115), donde 'caído 'presupone el proceso de 'cayendo', o resolución tomada... resoluta que fue (201), ya que como tomó la 'resolución' demostró ser 'resoluta', y gritó un apéate terrorista que mudó y demudó a Bonny. Bonny, mudo y demudado, se puso a salvo de un salto cangúrico, salvado... (249), donde 'mudo' y 'demudado' son el resultado de acciones anteriores de proceso: 'mudar', es decir, 'enmudecer' $y$ 'demudar', y 'salvado' es el resultado de 'ponerse a salvo'. Obsérvese, por otra parte, el juego fonético de mudó y mudo, incluso, demudó, frente a demudado.

Así como, al revés, casos de construcciones resultativas que funcionan como agentes causantes de construcciones de proceso, puntual: un Ferrari frenado es una afrenta que frena el frenesi (69).

Igualmente se registran casos de doble oposición, implícita, entre participio de pasado y adjetivo, que marca las fases de cumplido y resultativo-perfectivo, en contraste con la fase de adjetivo desligado: la erección completada (187), frente a *ompleta.

También se constata algún ejemplo de sinonimia funcional, textual, entre participio-adjetivo y sustantivo de su propia familia léxica, marcados como resultativos: prestado..., prestado... préstamos efectuados (243).

${ }^{61}$ A veces sólo se ofrece la perspectiva final en la relación entre forma personal y participio de pasado: poséeme para sentirme poseída (254).
} 
también morfológicamente, a través del sufijo derivativo $-a b l e^{62}$ : interminables sesiones... (49), por 'sesiones que no pueden ser terminadas', como pasiva, o quizá mejor, como antes, por 'sesiones que no se terminan', como media;

(g) es de notar que no siempre hay diátesis, sino deíxis inversa ${ }^{63}$ sintáctico-semántica, como en: medio país en huelga ${ }^{64}$ y el otro medio organizándola (178), o como en: que no es lo mismo llamar la guaracha que verla venir (233), o, que no es lo mismo Ilamar al diablo que verlo venir (239), o como en Benny no mira la mirada de las dos muchachas que lo miran (252);

(h) así mismo se muestran algunas tautologías ${ }^{65}$, tanto de tipo léxico: cruzadas en cruz (22), Fina refinada ${ }^{66}$ en una escuela suiza de refinamiento (49), le nacerá un nacidito $^{67}$ (57), entender bien entendido ${ }^{68}$ (65), tú eres un general generalizado (74), tan abrazado el abrazo que les dolió (104), la frustración por el frustrado fruto $^{69}$ (107), si tú haces una pista bien hecha ${ }^{70}$ (125), ensartadas por la admiración de una inteligencia admiradora (218); como de tipo semántico: adulterada su condición normal de mujeres grandes (33), por 'sufriendo adulteración'; o como de tipo léxico-semántico: un cuidado pormenorizado con atención atenta (132);

(i) en algunas ocasiones asistimos a participios prescindibles, ya que se subsumen en la preposición siguiente: mi cartel establecido de amante tempestuoso (28), por 'mi cartel de amante tempestuoso', separados por un muro hecho de bloques de la guaracha (98), por 'separados por un muro de bloques de la guaracha', un ronquido infinito y protestante que se arrancó de la garganta envuelta en llanto (118), por 'un ronquido infinito y protestante que se arrancó de la garganta en llanto', secuencia de los tres macharranes tendidos en una cama cubierta con colcha de motitas (140), por 'secuencia de los tres macharranes en una cama con colcha de motitas', la pared decorada con espejo (186), por 'la pared con espejo', como hermana y hermano vamos los dos cogidos de la mano (199), por 'como hermana y hermano vamos los dos de la mano';

\footnotetext{
${ }^{62}$ En este sufijo no basta sólo con que en la base del adjetivo en - ble se halle un verbo, sino que tal verbo tiene que tener unas características específicas como son las de ser transitivo o, más precisamente, la de llevar algún argumento que indique el tema o el objeto del predicado. (Cfr. Varela, 1996: 17).

${ }^{63}$ Hemos encontrado un caso muy curioso de deíxis inversa fonético-gráfica en que no es lo mismo maniobrar que obrar mani (239).

${ }^{64}$ Es decir, sufriéndola, estando en huelga. Por lo tanto, en ambas construcciones se mantiene huelga, como complemento directo; no hay recorrido diatético de complemento directo a sujeto paciente.

${ }^{65}$ El caso contrario sería el de la paradoja basada en un poliptoton, como en el modelito elegido sin elegir (41).

${ }^{66}$ Se busca un especial juego de significantes y significados entre el término expreso refinada y el término implícito homófono, no homógrafo: refina $\mathrm{y}$ *reFina, mucho más creativo y tensionador.

${ }_{67}^{67}$ Constituye una figura etimológica, o lo que en Latín se conoce como acusativo interno.

${ }^{68}$ Los ejemplos de este tipo constituyen pleonasmos, como, por ejemplo, también: me acuerdo siempre bien acordada (240).

${ }^{69}$ Ejemplo basado en la paronomasia. En ejemplos como este o como por prisas apresurado (255), queda más potenciada la tautología si se entiende el complemento como agente, que remite a un sujeto, y no como causa, que remite a un circunstante.

${ }^{70}$ Ejemplos pleonásticos de este tipo son abundantes, por ejemplo: uno cierra los ojos bien cerrados (195), Jean Paton y Guerlain destilaban unos aromas más destilados (227), me como esa recta bien comida (254).
} 
(j) la doble oposición entre participio de pasado regular e irregular, con especialización verbal para la forma regular, y especialización adjetiva o sustantiva para la forma irregular, se halla presente en algunos ejemplos aislados, tanto implícita: con gota de extracto de menta (48), donde se puede reconstruir la oposición: extracto (nombre) / * extraído (participio, sólo posible en el contexto de la novela como gota extraída de menta), como explícita: los macarrones rellenos de pasas y guisados con salsa de setas que se comen con berenjenas rellenas de ciruelas pasadas ${ }^{71}$ por huevo... (227);

(k) aparece la doble oposición, implícita, entre la forma culta y la forma patrimonial, en el siguiente doblete etimológico: boca ojival putrefacta por sapos y culebras (57), permutable por 'podrida';

(1) se observa abundancia de construcciones absolutas de participio como: rostros hermanados en el odio a Nixon y Pinochet (128), llegado el caso (233). Incluso con significado deponente activo: brillada la justicia (252), por 'haciendo brillar la justicia';

(m) finalmente, encontramos construcciones de participio que constituyen creaciones léxicas novedosas: por hendíadis: como pacientes contagiados, epidemiados de un virus (36), por 'contagiados de epidemia vírica'; por hipálage: como una Circe exquisitada con ramilletes copiosos (55), por 'que ha sido bendecida con el regalo de exquisitos ramilletes copiosos`; por integración léxica: Cupleterías de Sarita Montiel, mantonada y clavelada tras los cristales de alegres ventanales (83), por 'con mantón, envuelta en mantón, y con claveles, adornada con claveles', o la mano sensacionada (186), por 'llena de sensaciones`; por derivación léxica: unas instantáneas del Vietnam napalmizado (109), por 'rociado de napalm', o en el café parasolado Las Nereidas lo ve escupir (169), por 'café con parasol o rodeado de parasoles en su terraza', o ella andaba pantalonada con unos jeans pegadísimos (200), por 'andaba en pantalones ; por encadenamiento sinonímico ${ }^{72}$ de $^{\text {participios }}{ }^{73}$ y adjetivos: Doña Chon es mucho más que entrada en carnes. Doña Chon es mucho más que gorda... El mucho más en tercetos le da espesor de angelote atascado en grasas, angelote rebelado contra toda abstinencia bucal (58); o por encadenamiento de sinónimos de participios solos: Avergonzado, apesadumbrado, abrumado; por una inusual abundancia y repetición del esquema derivativo prefijal: el ritmo que el Macho Camacho ha puesto, impuesto, traspuesto y pospuesto (77); por doble creación léxica en el participio y en el complemento agente, constituyendo un pleonasmo: de dónde salió ese enano de carro choferado por choferito negrito (130); así como por sufijos seudoparticipales en -ada: por sentido figurado

\footnotetext{
${ }^{71}$ Además en este último caso se vuelve a abrir una oposición entre el sintema: "ciruelas pasas" y el sintagma "ciruelas pasadas" por huevo.

${ }^{72}$ Con otras formas no personales como el infinitivo también se nos ofrece metalingüísticamente la alternativa sinonímica por procedimiento sintético y analítico: para cenizar o convertir en ceniza (191)

${ }^{73}$ Los participios son necesarios porque expresan a través de su propio régimen verbal un contenido semántico complejo, que, solo con el adjetivo, sería imposible.
} 
eufemístico de origen metonímico: nalgada ${ }^{74}$ cariñosa al gato Mimoso (58), por 'palmada o patada a la nalga;

(n) en contraste con las expresiones novedosas, tenemos las frases hechas, tomadas de las Sagradas Escrituras, tal cual: santificado sea Tu Nombre (185-186), o ligeramente modificadas: escrito está en el libro de la vida (48), Por Dios y los que con él moran: las gracias y regracias sean dadas (99), donde lo subrayado muestra el guiño que Luis Rafael Sánchez hace desde el discurso libre al contexto textual. Incluso se rastrea la influencia del modelo latino en los dos casos de posposición del verbo ser en las construcciones de participio: santificado sea y escrito está.

\section{Conclusión}

De todo lo expuesto podemos concluir que en el componente léxico-semántico se constata una norma americana diferenciada de la norma española en muchos aspectos de la morfología léxica nominal. Estas diferencias adoptan fundamentalmente tanto la forma de variantes sociolectales como idiolectales. En los mecanismos empleados en la formación de palabras se aprecian fenómenos semánticos analógicos, tautológicos, sinonímicos, antonímicos, metonímicos, así como polisémicos a través de un cultivo destacado de la acronimia.

En cuanto al léxico estadounidense se registran casos de anglicismos-americanismos directos -vía discurso repetido y discurso libre-, y adaptados, con un rendimiento del calco sintáctico. En la adaptación de códigos, resulta relevante la presencia de Spanglish, con aproximaciones metalingüísticas y especializaciones semánticas. En cuanto al léxico aborigen hemos distinguido americanismos léxicos de americanismos semánticos -con subtipos de falsos amigos-, y, por otra parte, ambos tipos de americanismos con respecto a indigenismos léxicos. Por otra parte, resulta relevante el léxico erótico. Los ejemplos son tantos y tan ricos que nos han permitido una exhaustiva clasificación en: términos figurados metonímicos cultos, coloquiales-vulgares, familiares; términos figurados metafóricos cultos, coloquiales-vulgares, familiares; términos seudolatinos; y términos perónimos eufemísticos.

En el componente sintáctico-semántico hallamos un uso frecuente de elipsis: por reticencia oracional, por abreviación mediante acortamiento sintagmático nominal y por elipsis prepositiva, que caracterizan el español del Caribe. En relación a la esfera verbal se comprueba un avance de la transitividad, de la integración lingüística, del incremento prefijal, de la neutralización de formas verbales y de la especialización semántica.

Con respecto a las construcciones de participio se registran trece fenómenos caracterizados por la permutación con otras estructuras morfosintácticas, por el uso deponente, por la impropiedad semántica, por la doble perspectiva diatética activa-pasiva, marcada desde la misma o diferente familia léxica, por el doble enfoque pasivo-medio, por la deíxis inversa sintáctico-semántica, por la tautología léxico-semántica, por los participios prescindibles, por la especialización verbal o adjetiva, según sea el participio regular o

\footnotetext{
${ }^{74}$ Obsérvese que a diferencia de patada o zancada, con una perspectiva activa, nalgada ofrece un enfoque pasivo.
} 
irregular, por los dobletes etimológicos, por las construcciones absolutas, por las creaciones léxicas novedosas a través de: hendíadis, hipálage, integración léxica, derivación léxica, encadenamientos sinonímicos, sufijos seudoparticipiales, y, finalmente, por frases hechas dentro del discurso repetido.

\section{Referencias bibliográficas}

AA.VV. (1987): Actas del I Congreso Internacional sobre el español de América. Puerto Rico, Academia Puerto Riqueña de la Lengua Española.

AA.VV. (1993): Actas del Simposio sobre el español de España y el español de América. Virginia, University of Virginia.

Aleza Izquierdo, M. (2002): El español de América. Aproximación sincrónica. Valencia, Tirant lo Blanch.

Almela Pérez, R. (1999): Procedimientos de formación de palabras en español. Barcelona, Ariel.

Alvar López, M. (dir.) (1996): Manual de dialectología hispánica. El español de América. Barcelona, Ariel.

Bueso Fernández, I. (1999): Diferencias de usos gramaticales entre el español peninsular y el español de América. Barcelona, Edinumen.

Corominas, J. y J. A. Pascual (1955): Diccionario crítico etimológico castellano e hispánico. Madrid, Gredos. Edición de 1980.

Diccionarios de variantes del español: América Central y Caribe: Puerto Rico. http://www3.unileon.es/dp/dfh/jmr/dicci/0000.htm (octubre-diciembre, 2007)

Frago Gracia, J. A. (2003): El español de América. Cádiz, Universidad de Cádiz.

García Mouton, P. (2003): El español de América 1992. Madrid, CSIC.

Granda Gutiérrez, G. de (1968): Transculturación e interferencia lingüística en el Puerto Rico contemporáneo (1898-1968). Bogotá, Instituto Caro y Cuervo.

Granda Gutiérrez, G. de (1991): El español en tres mundos. Retenciones y contactos lingüisticos en América y África. Valladolid, Universidad de Valladolid.

Granda Gutiérrez, G. de (1994): Español de América, de África y hablas criollas hispánicas. Madrid, Gredos.

Guitarte, G. L. (1983): Siete estudios sobre el español de América. México, UNAM.

Haensch, G. (1993): Nuevo Diccionario de Americanismos. Colombia, Instituto Caro y Cuervo.

Haugen, E. (1956): Bilingualism in the Americas. University of Alabama Press.

Haugen, E. (1958): Language contact, en A.A.V.V.: Proceedings of the VIII Congress of Linguists. Oslo University Press.

Lipski, J. M. (1994): Latin American Spanish. New York, Longman.

Lipski, J. M. (2004): El español de América. Madrid, Cátedra.

Lipski, J. M. (2005): A history of Afro-hispanic language five centuries/five continents. Cambridge University Press.

Moliner, M. (2002): Diccionario de uso del español. Madrid, Gredos.

Morínigo, M. A. (1998): Nuevo Diccionario de americanismos e indigenismos. Ed. Claridad.

Lope Blanch, J. M. (1993): Ensayos sobre el español de América. México, UNAM.

López Morales, H. (1970): Estudio sobre el español de Cuba. Nueva York, Las Américas.

López Morales, H. (1991): "Desgaste léxico en el español de Puerto Rico. El proyecto Malaret". En Investigaciones léxicas sobre el español antillano. Santiago, PUCMM, págs. 169-196.

López Morales, H. (1994): Las Antillas. Madrid, Arco Libros. 
López Morales, H. (2001): "Estratificación social del tabú lingüístico: el caso de Puerto Rico". Estudios de Lingüistica Española, $n^{\circ} 13$. http://elies.rediris.es/elies13/lopez.htm (9-1-2008)

Moreno Fernández, F. (1993): La división dialectal del español de América. Alcalá de Henares, Universidad de Alcalá.

Ramos Huerta, O. (1997): Diccionario popular cubano. La Habana, Agualarga.

Real Academia Española (2001): Diccionario de la lengua española. Madrid, Espasa Calpe.

Real Academia Española (2005): Diccionario panhispánico de dudas. Madrid, Santillana.

Regionalismos de la lengua española: Diccionario de Regionalismos de la Lengua Española y Léxicos Regionales de la Lengua Española. www.hispanicus.com/drle (octubre-diciembre, 2007)

Rivarola, J. L. (2001): El español de América en su historia. Valladolid, Universidad de Valladolid.

Rosenblat, Á. (1965): El castellano de España y el castellano de América. Caracas, Cuadernos del Instituto de Filología "Andrés Bello".

Sala, M., et alii. (1982): El español de América. T. I, Léxico. Colombia, Instituto Caro y Cuervo.

Salvador Caja, G. (2001): "El español en España y el español en América". Nueva Revista de Política, Cultura y Arte, $n^{\circ} 74$. www.nuevarevista.net/2001/marzo/nr articulo74 4.htm (4-12-2007).

Sánchez, L. R. (1976). La guaracha del macho Camacho. Argentina, Ediciones de La Flor.

Sánchez, L. R. (1990): En cuerpo de camisa. Banta Co., Harrisonburg, VI, Editorial Cultural.

Seco, M., O. Andrés y G. Ramos (2005): Diccionario del español actual. Madrid, Aguilar.

Steel, B. (1999): Breve diccionario ejemplificado de americanismos. Madrid, Arco Libros.

Toro Mérida, J. (1984): Andalucismos léxicos en el español de América. Madrid, Universidad Complutense.

Torres Torres, A. (2001): El español de América. Barcelona, Universidad de Barcelona.

Zamora Munné, J. C. y J. M. Guitart (1988): Dialectología hispanoamericana: teoría, descripción, historia. Salamanca, Almar.

Varela Ortega, S. (1996): Fundamentos de morfología. Madrid, Síntesis.

Varela Ortega, S. (2005): Morfología léxica. La formación de palabras. Madrid, Gredos.

Weinreich, U. (1957): "Functional aspects of indian bilingualism", Word, XIII, 2, págs. 203-223.

Weinreich, U. (1958): "Research frontiers in bilingualism studies". En A.A.V.V.: Proceedings of the VIII International Congress of Linguists. Oslo University Press, págs. 786-795.

Zamora Vicente, A. (1986): "Estudios de dialectología hispánica". Verba, Anexo $n^{\circ} 25$. www.cervantesvirtual.com/servlet/SirveObras/01589525329802058321091/thm0001.htm

$(18-11-2007)$ 